\title{
A Magnetic Stimulation Examination of Orthographic Neighborhood Effects in Visual Word Recognition
}

\author{
Michal Lavidor ${ }^{1}$ and Vincent Walsh ${ }^{2}$
}

\begin{abstract}
The split-fovea theory proposes that visual word recognition is mediated by the splitting of the foveal image, with letters to the left of fixation projected to the right hemisphere $(\mathrm{RH})$ and letters to the right of fixation projected to the left hemisphere (LH). We applied repetitive transcranial magnetic stimulation (rTMS) over the left and right occipital cortex during a lexical decision task to investigate the extent to which word recognition processes could be accounted for according to the split-fovea theory. Unilateral rTMS significantly impaired lexical decision latencies to centrally presented words, supporting the suggestion that foveal
\end{abstract}

\section{INTRODUCTION}

When a person is fixating centrally, information presented to the right of fixation (in the right visual field, or RVF) is projected to the visual cortex of the left cerebral hemisphere (LH) and information presented to the left of fixation (in the left visual field, or LVF) is projected to the visual cortex of the right cerebral hemisphere (RH). However, it is not entirely clear how the visual half fields flank one another along the vertical meridian (Brysbaert, 1994). The current study aimed to look at this question by combining classical methods of behavioral studies with the application of repetitive transcranial magnetic stimulation (rTMS) over the occipital cortex, in order to test the impact of a left versus right lesion on the processing of foveal stimuli.

\section{The Cortical Representation of the Fovea}

Bilateral representation of the fovea has been demonstrated in cats (Stone, 1966) and monkeys (Stone, Leicester, \& Sherman, 1973), and the overlap appears primarily to be due to the presence of ipsilaterally projecting cells in the nasal hemiretina rather than to contralaterally projecting cells in the temporal hemiretina (Leventhal, Ault, \& Vitek, 1988). In addition to the anatomical evidence, the foveal sparing phenomenon (e.g., Zihl, 1989) is considered as evidence supporting

${ }^{1}$ University of Hull, ${ }^{2}$ University College London representation of words is split between the cerebral hemispheres rather than bilateral. Behaviorally, we showed that words that have many orthographic neighbors sharing the same initial letters ("lead neighbors") facilitated lexical decision more than words with few lead neighbors. This effect did not apply to end neighbors (orthographic neighbors sharing the same final letters). Crucially, rTMS over the RH impaired lead-, but not end-neighborhood facilitation. The results support the split-fovea theory, where the $\mathrm{RH}$ has primacy in representing lead neighbors of a written word. the bilateral representation of the fovea. Assuming that the fovea is bilaterally represented in the cerebral cortex, foveal sparing may be due to the foveal representation in the undamaged hemisphere, but estimates of the extent of the overlap vary: Bunt and Minckler (1977), for example, concluded that the bilateral representation covers the whole fovea-a visual area of $3^{\circ}$. Others have estimated the overlap to be smaller: Wyatt (1978), for example, suggested that the overlap covers only between $0.5^{\circ}$ and $1.5^{\circ}$ of the central representation. Some recent studies have also favored the bilateral, rather than split representation of the vertical midline with normal observers (Brandt, Stephan, Bense, Yousry, \& Dieterich, 2000) and also with hemianopia patients (Trauzettel-Klosinski \& Reinhard, 1998).

However, the majority of studies with human subjects have tended to support a split, rather than bilateral, cortical representation of the vertical midline. Harvey (1978), for example, presented visual targets to the left and right of fixation at various retinal loci and found a separation between crossed and uncrossed responding at all retinal loci. Targets located $0.25^{\circ}$ and $0.5^{\circ}$ from fixation, which should have fallen on the region of nasotemporal overlap, produced a reaction time (RT) difference between crossed and uncrossed responding just as large as at the other loci (e.g., $2^{\circ}$ and $3^{\circ}$ ) outside the overlap. If an area of functionally important overlap projecting to both cerebral hemispheres exists, then the need for interhemispheric crossing in word representation would be eliminated. Thus, the conclusion from 
Harvey's (1978) study, as well from similar studies (Lines \& Milner, 1983; Haun, 1978), was that the human fovea is not bilaterally represented or at least that the anatomical overlap does not appear to have functional consequences. In a recent study, magnetic resonance imaging (MRI) and visual field defects in patients with occipital lobe injury were correlated, leading Gray, Galetta, Siegal, and Schatz (1997) to conclude that the foveal region is unilaterally represented in the human primary visual cortex. Fendrich and Gazzaniga (1989; see also Fendrich, Wessinger, \& Gazzaniga, 1996) asked a commissurotomy patient to compare target figures presented $1^{\circ}$ or less from the retinal vertical midline with reference figures presented distal to the midline in the same or opposite visual field. The patient was required to judge whether the two stimuli were the same or different. It was found that targets in the same visual field as the reference were readily matched, but accuracy was only at chance levels for targets in the opposite field. These results were interpreted as indicating that the patient's fovea was effectively split with respect to the left and right cerebral hemispheres (see also Sugishita, Hamilton, Sakuma, \& Hemmi, 1994). In a recent study with healthy observers, visual targets presented to the LVF and RVF evoked responses in the contralateral occipital (and medial parietal) areas, even when the horizontal eccentricity was $0^{\circ}$ (Portin \& Hari, 1999). Behaviorally, it has been established that, at least for brief presentation of foveal stimuli (up to $200 \mathrm{msec}$ ), there is no functional overlap along the vertical meridian (Gazzaniga, 2000).

Recently, several behavioral studies with healthy participants have tested directly the predictions of the splitfovea theory and concluded that there are no indications that the center of the visual field is bilaterally represented (Brysbaert, 1994; Brysbaert, Vitu, \& Schroyens, 1996). The idea in these experiments was to look at robust, previously reported visual field differences but with a different definition of visual fields, where RVF starts from $0^{\circ}$ to the right of fixation and LVF from midline to the left. Employing this definition of visual fields, Lavidor, Ellis, Shillcock, and Bland (2001) have reported word length effects in the left side of centrally presented words (the initial letters) but not the right side (the final letters), replicating the well-established finding of word length and hemifield interaction (Ellis, Young, \& Anderson, 1988).

The split fovea has been successfully implemented in a connectionist model (Shillcock, Ellison, \& Monaghan, 2000). Shillcock et al. (2000) investigated the optimal processing of visually presented words in a connectionist model employing a split functional architecture. The results of their algorithm demonstrated reading behavior that is observed in psycholinguistic experiments including the optimal viewing position (OVP; O'Regan, 1981) and the failure to fixate shorter words (Rayner, 1998).
In light of the evidence favoring the split fovea, we argue that aspects of letter and word recognition that are more characteristic of the right cerebral hemisphere will also be reflected in the processing of the initial letters of words, while aspects of letter and word recognition that are more characteristic of the left hemisphere (LH) will apply to the ends of words. In this article, the investigated variable was orthographic neighborhood $(N)$, recently reported as having asymmetric effects in the two cerebral hemispheres (Lavidor \& Ellis, 2002a, 2002b; Rubinstein, Henik, \& Dronkers, 2001).

\section{Orthographic Neighborhood}

$N$ is defined as the number of same-length words differing from a target word by one letter (i.e., neighbors) (Coltheart, Davelaar, Jonasson, \& Besner, 1977). By this definition, the word marsh, for example, has two neighbors, harsh and march (Forster \& Shen, 1996). In contrast, the word cover has 13 neighbors (including coven, covet, cower, hover, lover, mover, and rover). Previous studies have shown, in general, facilitation effects for lexical decision for words with larger $N$ s (so-called friendly words) (Andrews, 1997; Laxon, Coltheart, \& Keating, 1988; Laxon, Masterson, \& Moran, 1994). $N$ effects are robust when frequency, regularity, and age of acquisition are controlled (Morrison \& Ellis, 2000), although frequency of the neighboring words may interact with $N$ (Perea \& Pollatsek, 1998; Segui \& Grainger, 1990). Theoretical explanations of $N$ effects generally invoke the notion that a written word can activate not only its own lexical entry but also the entries for other words of similar appearance. In certain conditions at least, activating those other lexical entries can facilitate the processing of the target word. Andrews (1997) proposed an explanation for neighborhood size effects in terms of McClelland and Rumelhart's (1981) interactive activation model of visual word recognition, suggesting that the processing units responsible for identifying letters in words receive more top-down support from lexical units in the case of words with many neighbors than in the case of words with few neighbors.

\section{Orthographic Neighborhood Effects in a Split-Fovea Model}

In the split-fovea model, the RH is assumed to reflect $N$ effects invoked by the initial letters (represented in the LVF), and the LH would, symmetrically, reflect $N$ of the end letters, represented in the RVF.

However, words are not simple symmetrical stimuli, and initial letters of words may be more informative than their endings. For example, informative letter sequences at the beginning of a word lead to a deviation of the landing positions of the saccadic eye movements toward the word beginning (Doré \& Beauvillain, 
1997; Beauvillain, Doré, \& Baudouin, 1996). Bryden, Mondor, Loken, Ingleton, and Bergstrom (1990) found that subjects identified significantly more words with terminal deletions (missing letter or bigram at word's ending, e.g., marc_) than words with an initial deletion (missing letters at the word's beginning, e.g., _arch). It has been proposed that the structure of the mental lexicon may not easily allow access via the end of the word, even if it is highly informative (O'Regan, LevySchoen, Pynte, \& Brugaillere, 1984).

The different contribution of initial letters to word identification in comparison to final letters implies that "orthographic neighbors are not all equal" (Perea, 1998). Orthographic neighbors that share the initial letters with a target (we will term them lead neighbors [LN], e.g., anger-angel) may facilitate target recognition more than orthographic neighbors that share the final letters with a target (end neighbors ${ }^{1}$ [EN], e.g., aloud-cloud). At the level of processing in the occipital cortex, it is more likely that the $\mathrm{RH}$ activates lead neighbors but the LH does not necessarily activate end neighbors. This hypothesis received some indirect support recently by Lavidor and Ellis (2002a, 2002b) and Rubinstein et al. (2001), who found robust $N$ effects in the LVF, but not in the RVF. The aim of the current study was therefore to look into the question of orthographic neighborhood effects within the context of the split-fovea theory by temporarily disrupting processing in the $\mathrm{RH}$ and $\mathrm{LH}$ with repetitive TMS.

\section{Transcranial Magnetic Stimulation and Visual Word Recognition}

Several types of visual recognition tasks have been disrupted by TMS applied over the occipital pole at various delays from the letter or the word presentation onset (e.g., Cowey \& Walsh, 2000; Corthout, Uttl, Walsh, Hallett, \& Cowey, 1999; Corthout, Uttl, Ziemann, Cowey, \& Hallett, 1999; Kammer, 1999; Kastner, Demmer, \& Ziemann, 1998; Amassian et al., 1989, 1998; Amassian, Cracco, et al., 1993, Amassian, Maccabee, et al., 1993). For example, single-letter identification was impaired when TMS was applied over the striate visual cortex (Amassian et al., 1989). Recently, we showed that rTMS over the right occipital cortex has a significant inhibitory effect on lexical decision performance to LVF targets but no significant effect on RVF targets. The complementary pattern of rTMS effects was obtained with LH stimulation, which significantly impaired lexical decision to RVF but not LVF targets (Lavidor, Ellison, \& Walsh, in press).

\section{RESULTS}

RTs and the percentage of incorrect responses for words are summarized in Table 1.

\section{Target Lexicality}

Target lexicality had a significant effect on RTs, $F(1,7)=$ 5.22, $p<.05$, and accuracy, $F(1,7)=8.3, p<.01$, with

Table 1. Mean RTs and Standard Deviations for Word Targets (in msec) and Percentage of Error as a Function of Target Orthographic Neighborhood Size and Site of Magnetic Stimulation

\begin{tabular}{|c|c|c|c|c|}
\hline & $\begin{array}{l}\text { Many Lead-N, } \\
\text { Many End-N }\end{array}$ & $\begin{array}{l}\text { Many Lead-N, } \\
\text { Few End-N }\end{array}$ & $\begin{array}{l}\text { Few Lead-N, } \\
\text { Many End-N }\end{array}$ & $\begin{array}{l}\text { Few Lead-N, } \\
\text { Few End-N }\end{array}$ \\
\hline \multicolumn{5}{|l|}{ No-TMS } \\
\hline Mean RT & 425 & 435 & 462 & 477 \\
\hline$S D$ & 46 & 57 & 72 & 60 \\
\hline$\%$ error & 0 & 0 & 2 & 2 \\
\hline \multicolumn{5}{|l|}{ RH TMS } \\
\hline Mean RT & 505 & 501 & 485 & 490 \\
\hline$S D$ & 87 & 55 & 77 & 73 \\
\hline$\%$ error & 5 & 8 & 6 & 0 \\
\hline \multicolumn{5}{|l|}{ LH TMS } \\
\hline Mean RT & 476 & 470 & 508 & 513 \\
\hline$S D$ & 92 & 55 & 73 & 66 \\
\hline$\%$ error & 7 & 4 & 6 & 10 \\
\hline
\end{tabular}

Lead- $N=$ orthographic lead-neighbors; End- $N=$ orthographic end-neighbors. 
faster and more accurate responses to words (478 msec, $96 \%$ correct) than to nonwords (513 msec, $89 \%$ correct). These results are in accordance with previous behavioral literature (Chiarello, 1988; Ellis et al., 1988). Because the neighborhood effects for words were the focus of the current study, the rest of the analyses was performed only for word targets.

\section{Reaction Times}

The application of rTMS had a significant effect, $F(2,14)=10.5, p<.01$, with RTs being slowed when TMS was applied to the LH (mean $=492 \mathrm{msec}$ ) or to the RH site (mean $=495 \mathrm{msec}$ ) compared with the no-TMS mean of 449 msec (all post hoc differences were Bonferroni corrected to $p<.05$ ). Orthographic neighborhood group had a significant effect on response latency, $F(3,21)=5.93, p<.01$, with faster responses to words with many $\mathrm{LN}$ (many $\mathrm{LN}+$ many $\mathrm{EN}=468 \mathrm{msec}$, many $\mathrm{LN}+$ few $\mathrm{EN}=469 \mathrm{msec})$ compared with responses to words with few LN (few LN + many EN = 485 msec, few $\mathrm{LN}+$ few $\mathrm{EN}=493 \mathrm{msec}$ ).

The interaction between rTMS site (RH, LH) and orthographic neighborhood was also significant, $F(6,42)=3.42, p<.05$. Separate analyses testing the neighborhood effect under the three rTMS conditions revealed significant $N$ effect when rTMS was not applied, $F(3,21)=5.1, p<.05$, and when the application site was in the LH, $F(3,21)=4.8, p<.05$. However, the orthographic neighborhood effect was abolished by RH rTMS, $F(3,21)=1.3, n s$, that is, the facilitation gained for words with many LN was impaired only when rTMS was applied to the RH. This can be clearly seen in Figure 1, which presents rTMS effect sizes (the difference in RTs from the no-TMS condition). In the RH site, the rTMS effect (i.e., the inhibition caused by rTMS) is significantly larger for words with many LN when compared with words with few LN. However, the rTMS effect when stimulating the LH site caused equal (small, yet significant) inhibition for all word types. Having few or many EN did not affect performance.

\section{Error Rates}

The application of rTMS had an overall significant effect on error rates, $F(2,14)=6.3, p<.05$, with significantly more errors when TMS was applied to the LH (mean = $6.7 \%$ ) or to the RH site (mean $=5 \%$ ) compared with the no-TMS mean of 1\%. Orthographic neighborhood neither interacted with rTMS site nor directly affected error rates to word stimuli.

\section{DISCUSSION}

In a lexical decision experiment with rTMS applied to the left and right visual cortex, we investigated the function of the RH in terms of a split-word recognition

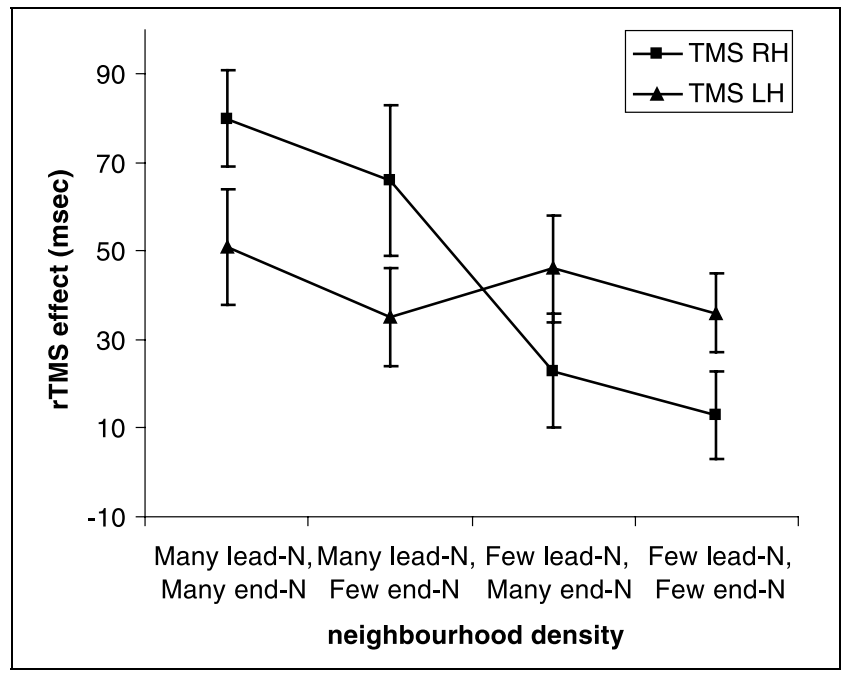

Figure 1. rTMS effect size for RTs for words as a function of word orthographic neighborhood size and magnetic stimulation site. $\mathrm{RH}$ rTMS significantly impairs responses to stimuli with many lead neighbors (LN) but had little effect when words had few LN. LH rTMS produced an equal (small, yet significant) inhibition for all word types.

model. In view of the evidence supporting the splitfovea theory (Gazzaniga, 2000; Shillcock et al., 2000; Portin \& Hari, 1999; Gray et al., 1997; Brysbaert, 1994), the starting point of this investigation was that when a person is fixating centrally, information presented to the right of fixation (in the RVF) is projected to the visual cortex of the left cerebral hemisphere (LH) due to the anatomical arrangement of the human visual system. Conversely, information presented to the left of fixation (in the LVF) is projected to the visual cortex of the right cerebral hemisphere. Assuming a splitfoveal representation, we specifically investigated the importance of the $\mathrm{RH}$ in processing the initial letters of a written word and of the $\mathrm{LH}$ in representing the final letters of centrally presented targets. We presented words that had many or few lead neighbors (samelength words that shared the initial letters) and many or few end neighbors (same-length words that shared the final letters with a target word). Behaviorally, leadneighborhood density facilitated performance rather than end-neighborhood density. However, this facilitation was significantly impaired when rTMS was applied to the RH, but not to the LH. Thus, the ability to respond to the initial letters is dependent upon $\mathrm{RH}$ processes. Orthographic neighborhood density was selected as a variable of interest that may characterize the $\mathrm{RH}$ processes in word recognition under a splitfovea constraint due to the greater orthographic neighborhood effects in the RH but not in the LH (Lavidor \& Ellis, 2002a, 2002b; Rubinstein et al., 2001).

One concern that may account for the results is a possible systematic bias towards a certain visual field. However, the stimuli were all centrally presented, and usually subjects are successful in maintaining fixation to 
foveal stimuli, and only a small percentage of trials are not properly fixated (less then 1\%, see, for instance, Rayner, 1998). Systematic shifts of eye position to RVF were reported by one research group (Jordan, Patching, \& Milner, 2000; Patching \& Jordan, 1998); however, most eye-movement researchers would report, if at all, an LVF bias due to the OVP (the tendency to fixate slightly to the left of fixation, see O'Regan, 1981). More specifically, in a companion lexical decision and TMS study (Lavidor et al., in press), we have monitored fixation during the TMS sessions and failures to fixate centrally presented words occurred in $0.09 \%$ of all trials. Therefore, one can preclude the possibility that the current data reflect systematic RVF shifts.

Before carrying out a TMS procedure, it was necessary to obtain reliable baseline effects with the behavioral task. Word and nonword targets were briefly presented in the center of the monitor while right-handed participants made lexical decision judgments. The results were compatible with those of numerous previous lateralization experiments (Iacoboni \& Zaidel, 1996; Chiarello, 1988; Ellis et al., 1988); words were responded to faster and more accurately than nonwords, and we found the predicted orthographic lead-neighborhood effect.

The rTMS effects we found for briefly presented targets are consistent with other rTMS findings with occipital stimulation in which TMS is only able to disrupt perceptual judgments if the relative duration of presentation is short (e.g., Amassian et al., 1989), stimuli are close to luminance-detection thresholds (Miller, Fendrich, Eliassen, Demirel, \& Gazzaniga, 1996) or both (see Kammer \& Nusseck, 1998; see also Walsh \& Cowey, 2000; Walsh \& Pascual-Leone, 2003, for details of the relationship between stimuli and the temporal duration of TMS effects). In the present study, error rates were affected by rTMS application; however, they were not sensitive to the manipulation of orthographic neighborhood. Because performance was nearly errorless (particularly for words), the lack of $N$-related effects for the accuracy measure may be due to ceiling level performance. Although errors may be a useful measure of performance close to threshold, it has been difficult to obtain errors in cognitive tasks with TMS (see Walsh \& Cowey, 1998; Walsh \& Pascual-Leone, 2003, for methodological details).

The significant behavioral disruption induced by TMS during the presentation of targets at the center of fixation at first sight suggests it is unlikely that two complete copies of the centrally presented word were processed in each hemisphere. However, independent representations do not preclude interactions between the two hemispheres, and when the word is presented in the region of greatest representational overlap (i.e., at fixation in the midline), it may be the case that any disruption to word processing may interfere with either competition or cooperation between the hemispheres that is a feature of normal processing (e.g., Hilgetag,
Theoret, \& Pascual-Leone, 2001; Fierro et al., 2000; Walsh, Ellison, Ashbridge, \& Cowey, 1999; Seyal, Ro, \& Rafal, 1995). Thus, the results we obtained do not rule out the possibility of some functional significance behind the anatomical evidence of bilateral representation of the fovea. However, interhemispheric interactions cannot explain the significant interaction we obtained between orthographic neighborhood of the initial letters and rTMS site. One other possibility is a different model that is a weaker version of the split model, that is, where both hemispheres maintain a strong representation of the contralateral stimuli and a weak representation of the ipsilateral stimuli of centrally presented targets. Even if this is the case, our results show clearly that the supposedly "weaker" letters that are ipsilateral to the unstimulated hemisphere did not affect performance. They may be there; however, neighborhood effects of the "weaker" letters were not found, so functionally, the split is complete. We have shown how rTMS over the RH can interfere selectively with the processing of the initial letters of centrally presented words (but not of final letters). This is a strong test of the split representation of the fovea theory.

In summary, this investigation of the split-foveal representation contributes to the emerging literature that is providing a starting point for the reconceptualization of visual word recognition research in terms of the splitting of the fovea. The results reported here provide support for the theory that during fixation, letters to the left of fixation are projected to and processed in the right cerebral hemisphere and letters to the right of fixation are projected to and processed in the left cerebral hemisphere. The challenge for this new area of visual word recognition research is to integrate this theory with the more complex tasks involved in the reading of connected text.

\section{METHODS}

\section{Transcranial Magnetic Stimulation Equipment}

The stimulator used was a MagStim (Super Rapid model) with four external boosters (maximum output $2 \mathrm{~T}$ ). Magnetic stimulation was applied at $65 \%$ of the maximum using a figure-of-eight $70-\mathrm{mm}$ coil $(1.3 \mathrm{~T})$. The double coil windings in the figure-of-eight coil carry two currents in opposite directions and at the midpoint of the coil where the two loops meet, there is a localized summation of current. A focal electric current is induced in the cortex by the magnetic pulse that undergoes minimal attenuation by the intervening soft tissue and bone. Previous studies have demonstrated that magnetic stimulation using this type of coil can produce functionally dissociable effects when moving the coil by $0.5-1 \mathrm{~cm}$ on the scalp (Brasil-Neto, McShane, Fuhr, Hallett, \& Cohen, 1992). The center of the coil was positioned over the site to be stimulated such that the windings were to the left and to the right of it and the handle of 
the coil pointed vertically. The level of stimulation (65\%) selected in this article matches the conditions used in a previous study of split-foveal processing with TMS (Lavidor et al., in press).

\section{Participants}

Eight native English-speaking participants, four women and four men, took part in the experiment. All of the participants had normal or corrected-to-normal vision and were aged between 19 and 30 (mean 23.5). All the participants were right-handed and scored at least 85 according to the Edinburgh Handedness Inventory (Oldfield, 1971), with mean score of 96. Participants received £10 for their participation.

Before taking part in the experiment, participants were given an information leaflet that explained the procedure to be used and were given at least $24 \mathrm{hr}$ to decide whether they wished to participate. All participants signed a consent form and reported absence of epilepsy or any other neurological conditions in themselves and their family. The Oxford Research Ethical Committee granted ethical committee approval for all procedures.

\section{Stimuli}

The experimental stimuli consisted of 120 words and 120 nonwords all containing six letters. The stimuli were selected such that they would match one of four stimulus groups created from the four possible combinations of many and few lead and end neighbors according to the following criteria:

1. Lead neighbors (LN): The number of six-letter words that could be made beginning with the same first three letters of each stimulus word or nonword. ${ }^{2}$ The range of this variable was 15-40 neighbors for the many LN group and 0-7 neighbors for the few LN group.

2. End neighbors (EN): The number of six-letter words that could be made ending with the same final three letters of the stimuli. The range of this variable was 15-70 neighbors for the many EN group and 0-10 neighbors for the few EN group.

Group 1 stimuli (30 words and 30 nonwords, e.g., castle) had many lead neighbors (mean number of $\mathrm{LN}=28.9)$. This group of words also had many end neighbors (mean number of $\mathrm{EN}=39.4$ ). Group 2 stimuli (again 30 words and 30 nonwords, e.g., cheese) had many LN (mean = 30) but few EN (mean =9). Group 3 stimuli (e.g., cement) had few LN (mean = 3) and many EN (mean = 41). Group 4 (e.g., coffin) had few LN (mean $=4$ ) and few $\operatorname{EN}($ mean $=7$ ).

The word stimuli in each of the four groups were matched according to written frequency (frequency norms by Kucera \& Francis, 1967, mean frequency = 10.00 per million), imageability (Coltheart, 1981, mean = 363 , from a 100-700 scale), and number of orthographic neighbors (Quinlan, 1993, mean $=1.6$ neighbors), so that the stimulus groups did not differ on any of these categories. The nonwords were generated from another word pool of six-letter words, with similar frequency range, by changing one or two letters, such that the nonwords were pronounceable (and had many and few LN and EN as described).

Each of the four groups was further divided to three subgroups (20 stimuli in each subgroup), matched in frequency, imageability, and $N$. The subgroups were randomly assigned to one of the three TMS conditions (no-TMS, TMS to the LH, or TMS to the RH). During the experiment, each stimulus was repeated twice in two different TMS conditions.

The stimuli were presented in Times Roman font, size 16 , such that target width was $1.6^{\circ}$ when viewed from $70 \mathrm{~cm}$. The targets were black on a light gray background and were presented in the center of the screen for $150 \mathrm{msec}$.

\section{Experiment}

We applied rTMS over the left and right occipital cortex during a lexical decision task to investigate the extent to which word recognition processes could be accounted for according to the split-fovea theory. The targets we presented differ in orthographic neighborhood density. The experiment tested the predictions that (1) stimulating the right or left sites would impair lexical decision to centrally presented words, (2) words with many lead neighbors would be processed faster than words with few lead neighbors, but end neighbors would have a smaller, if any, effect, and, crucially, (3) stimulating the $\mathrm{RH}$ site would decrease the leadneighborhood effect, but LH TMS would not inhibit the end-neighborhood effect. This last prediction is based on the split-fovea theory and the asymmetric orthographic neighborhood effect.

A $4 \times 3 \times 2$ factorial design (Orthographic Neighborhood: many LN + many EN, many LN + few EN, few $\mathrm{LN}+$ many EN, and few $\mathrm{LN}+$ few EN) $\times($ TMS: no stimulation, RH stimulation, or LH stimulation $) \times($ target lexicality: word, nonword) was used in a withinsubjects design. Dependent variables were RT and percentage of incorrect responses. The application of repetitive TMS was presented in alternating blocks of single-hemisphere stimulation. The other variables were randomly applied.

\section{Procedure}

Pre-experiment: Induction of Stationary Phosphenes

Before attempting to disrupt word processing, the sites to be stimulated were defined by eliciting phosphenes from the occipital cortex to ensure that hemispheric stimulation selectively affected contralateral visual field processing. Participants wore a latex swimming cap and 
Figure 2. Experimental time line of the task used in this study. Stimuli were presented for $150 \mathrm{msec}$, and rTMS was applied for $500 \mathrm{msec}$ at target onset.

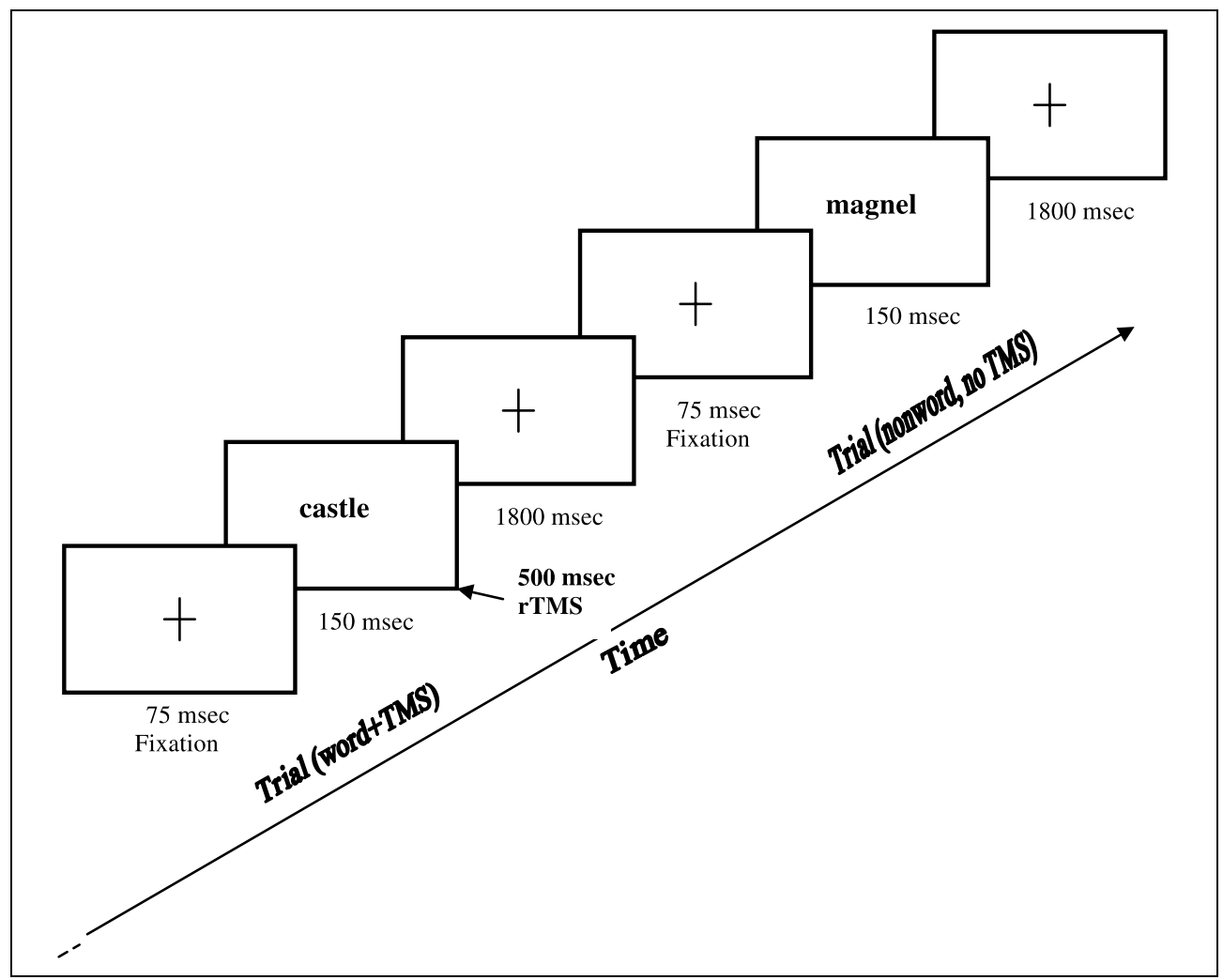

sat with their head supported by a chin rest and head strap in order to secure head position and stabilize fixation. Stimulation sites were the right and left cortices. The upper edge of the inion was marked on the cap, and another point (the reference point) was marked $2 \mathrm{~cm}$ above it. The occipital hemispheric sites that were marked on the cap were $1.5 \mathrm{~cm}$ to the left of the center point (LH site) and $1.5 \mathrm{~cm}$ to the right of the central point (RH site). The coordinates were selected initially based on previously successful studies with TMS, which reported stationary phosphenes and suppression of visual perception tasks with TMS at similar sites (Lavidor et al., in press; Pascual-Leone \& Walsh, 2001; Cowey \& Walsh, 2000; Kammer, 1999; Stewart, Battelli, Walsh, \& Cowey, 1999; Stewart, Ellison, Walsh, \& Cowey, 2001; Kastner et al., 1998; Amassian et al., 1989).

At the phosphene stage, we located the stimulation sites with TMS delivered at a frequency of $2 \mathrm{~Hz}$ and between $60 \%$ and $90 \%$ of stimulator output. In a darkened room, participants closed their eyes while TMS was delivered to the RH and LH points. Participants were asked to indicate whenever they saw a phosphene and to describe its position in space. TMS was applied at increasing intensities until participants reported seeing phosphenes regularly and reliably. For some participants, the magnetic stimulation sites were changed in a "win-stay/lose-shift" paradigm (see Ashbridge, Walsh, \& Cowey, 1997) to locate regions on the scalp that resulted in phosphene perception. The mean distance to the left of the central point was $1.56 \mathrm{~cm}$ and the mean distance to the right of the central point was $1.55 \mathrm{~cm}$. All but one participant reported left to central phosphenes when the RH was stimulated and right to central phosphenes when the LH was stimulated. For the main experiment, we used the effective phosphene sites for each participant with a fixed 65\% of the stimulator output, a level selected based on previous experiments and found to be sufficient to disrupt perception without masking stimuli with overt phosphenes. For the participant who failed to see phosphenes, we used the mean values of the group as stimulation sites. This subject was included because he had taken part in several previous experiments in which visual suppression was induced and because visual effects have been coregistered with his anatomical MRI scan.

\section{Main Experiment}

At the experimental stage, we applied rTMS with 65\% of the stimulator output at $8-\mathrm{Hz}$ frequency for 500 msec from the onset of the target presentation while participants were performing the lexical decision task. Stimulus presentation was controlled by an IBM Pentium II computer on a $17^{\prime \prime}$ SVGA display with 100-Hz refresh rate.

The experimental trials were employed in 8 blocks, 60 trials in each block, with a total of 480 trials per participant. While orthographic neighborhood and target lexicality (word or nonword) were randomly presented, magnetic stimulation sites were fixed per block. 
Thus, we had four blocks with rTMS applied to the right visual cortex and four blocks with rTMS applied to the left visual cortex, in alternating order. In each block, rTMS was given in alternating trials to allow 4-sec delay between successive rTMS trials. Thus, in each block, every rTMS trial was followed by a non-TMS trial and so forth. The rationale for this design was to maintain stimulus presentation at a fast rate typical of lateralization studies. Each of the 240 stimuli was presented twice (in separate blocks), once in the no-TMS condition and once with RH or LH stimulation (order of stimulation was counterbalanced across participants).

Each trial began with a fixation cross appearing in the center of the screen for $75 \mathrm{msec}$. For the first trial, the cross remained visible for $2000 \mathrm{msec}$ until the onset of the target. The cross would again reappear for $1800 \mathrm{msec}$, waiting for the participant's response. Whatever the response, after 1800 msec, a new trial sequence would begin. Targets were briefly presented for $150 \mathrm{msec}$ at the center of the screen (either a word or a nonword) in a random order (see the time line of the experiment in Figure 2). The participant's task was to decide, as quickly and as accurately as possible, whether the stimulus was a legal English word or a nonword. Participants responded by pressing one of two available response buttons with two fingers of the right hand. For half of the participants, the response "word" was made by pressing the right button, and "nonword" by pressing the left button. For half of the participants, the response keys were reversed. Each session began with 12 practice trials of centrally presented letter strings, where the task was to perform a lexical decision. Participants were informed that central fixation was important.

\section{Acknowledgments}

This study was supported by the European Commission, by a Marie Curie fellowship grant (Contract No. HPMF-CT-200000787), by a Wellcome grant, and by a visit grant from Brain awarded to M. Lavidor. V. Walsh is supported by the Royal Society. Related support was granted by the Medical Research Council and the Dr. Hadwen Research Trust.

Reprint requests should be sent to Michal Lavidor, Department of Psychology, University of Hull, Hull HU6 7RX, England, UK, or via e-mail: m.lavidor@hull.ac.uk.

\section{Notes}

1. End neighbors are also termed body neighbors by Ziegler and Perry (1998).

2. This definition of $\mathrm{LN}$ and $\mathrm{EN}$ as same-length words that share initial or final letters with a target comprises an implicit assumption that word length is encoded initially by both hemispheres, despite the split process. Elsewhere (Lavidor, Ellis, Shillcock, \& Hayes, in preparation), we have shown the preservation of word length coding when four-letter lead neighbors primes were more effective than seven-letter primes to four-letter target words. The underlying mechanism that enables the bilateral speeded coding of word length when at the initial stages the word is split between the two hemispheres requires further study. One possibility is the magnocellular pathway, which encodes low spatial frequency information and in which neuronal latencies are short in early visual processing (see Stein \& Walsh, 1997; Stuart \& Lovegrove, 1992).

\section{REFERENCES}

Amassian, V. E., Cracco, R. Q., Maccabee, P. J., Cracco, J. B., Rudell, A. P., \& Eberle, L. (1989). Suppression of visual perception by magnetic coil stimulation of human occipital cortex. Electroencephalography and Clinical Neurophysiology, 74, 458-462.

Amassian, V. E., Cracco, R. Q., Maccabee, P. J., Cracco, J. B., Rudell, A. P., \& Eberle, L. (1993). Unmasking human visual-perception with the magnetic coil and its relationship to hemispheric asymmetry. Brain Research, 605, 312-316.

Amassian, V. E., Cracco, R. Q., Maccabee, P. J., Cracco, J. B., Rudell, A. P., \& Eberle, L. (1998). Transcranial magnetic stimulation in the study of the visual pathway. Journal of Clinical Neurophysiology, 15, 288-304.

Amassian, V. E., Maccabee, P. J., Cracco, R. Q., Cracco, J. B., Rudell, A. P., \& Eberle, L. (1993). Measurement of information-processing delays in human visual cortex with repetitive magnetic coil stimulation. Brain Research, 605 , 317-321.

Andrews, S. (1997). The effect of orthographic similarity on lexical retrieval: Resolving neighborhood conflicts. Psychonomic Bulletin and Review, 4, 439-461.

Ashbridge, E., Walsh, V., \& Cowey, A. (1997). Temporal aspects of visual search studied by transcranial magnetic stimulation. Neuropsychologia, 35, 1121-1131.

Beauvillain, C., Doré, K., \& Baudouin, V. (1996). The "center of gravity" of words: Evidence for an effect of the word-initial letters. Vision Research, 36, 589-603.

Brandt, T., Stephan, T., Bense, S., Yousry, T. A., \& Dieterich, M. (2000). Hemifield visual motion stimulation: An example of interhemispheric crosstalk. NeuroReport, 11, 2803-2809.

Brasil-Neto, J. P., McShane, L. M., Fuhr, P., Hallett, M., \& Cohen, L. G. (1992). Topographic mapping of the human motor cortex with magnetic stimulation: Factors affecting accuracy and reproducibility. Electroencephalography and Clinical Neurophysiology, 85, 9-16.

Bryden, M. P., Mondor, T. A., Loken, M., Ingleton, M. A., \& Bergstrom, K. (1990). Locus of information in words and the right visual field effect. Brain and Cognition, 14, 44-58.

Brysbaert, M. (1994). Interhemispheric transfer and the processing of foveally presented stimuli. Behavioral Brain Research, 64, 151-161.

Brysbaert, M., Vitu, F., \& Schroyens, W. (1996). The right visual field advantage and the optimal viewing position effect: On the relation between foveal and parafoveal word recognition. Neuropsychology, 10, 385-395.

Bunt, A. H., \& Minckler, D. S. (1977). Foveal sparing: New anatomical evidence for bilateral representation of the central retina. Archives of Ophthalmology, 95, $1445-1447$.

Chiarello, C. (1988). Lateralization of lexical processes in the normal brain: A review of visual half-field research. In H. A. Whitaker (Ed.), Contemporary reviews in neuropsychology (pp. 36-76). New York: Springer-Verlag.

Coltheart, M. (1981). The MRC psycholinguistic database. Quarterly Journal of Experimental Psychology, 33A, 497-505.

Coltheart, M., Davelaar, E., Jonasson, J. T., \& Besner, D. 
(1977). Access to the internal lexicon. In S. Dornic (Ed.), Attention and performance VI: The psychology of reading (vol. 6, pp. 535-555). London: Academic Press.

Corthout, E., Uttl, B., Walsh, V., Hallett, M., \& Cowey, A. (1999). Timing of activity in early visual cortex as revealed by transcranial magnetic stimulation. NeuroReport, 10, 1-4

Corthout, E., Uttl, B., Ziemann, U., Cowey, A., \& Hallet, M. (1999). Two periods of processing in the (circum) striate visual cortex as revealed by transcranial magnetic stimulation. Neuropsychologia, 37, 137-145.

Cowey, A., \& Walsh, V. (2000). Magnetically induced phosphenes in sighted, blind and blindsighted observers. NeuroReport, 11, 3269-3273.

Doré, K., \& Beauvillain, P. (1997). Latency dependence of word-initial letter integration by the saccadic system. Perception and Psychophysics, 59, 523-533.

Ellis, A. W., Young, A. W., \& Anderson, C. (1988). Modes of word recognition in the left and right cerebral hemispheres. Brain and Language, 35, 254-273.

Fendrich, R., \& Gazzaniga, M. S. (1989). Evidence of foveal splitting in a commissurotomy patient. Neuropsychologia, 27, $273-281$.

Fendrich, R., Wessinger, C. M., \& Gazzaniga, M. S. (1996). Nasotemporal overlap at the retinal vertical meridianinvestigations with a callosotomy patient. Neuropsychologia, 34, 637-646.

Fierro, B., Brighina, F., Oliveri, M., Piazza, A., La Bua, V., Buffa, D., \& Bisiach, E. (2000). Contralateral neglect induced by right posterior parietal rTMS in healthy subjects. NeuroReport, 11, 1519-1521.

Forster, K. I., \& Shen, D. (1996). No enemies in the neighborhood: Absence of inhibitory neighborhood effects in lexical decision and semantic categorization. Journal of Experimental Psychology: Learning, Memory, and Cognition, 22, 696-713.

Gazzaniga, M. S. (2000). Cerebral specialization and interhemispheric communication. Brain, 123, 1293-1326.

Gray, L. G., Galetta, S. L., Siegal, T., \& Schatz, N. J. (1997). The central visual field in homonymous hemianopia-evidence for unilateral foveal representation. Archives of Neurology, 54, 312-317.

Harvey, L. O., Jr. (1978). Single representation of the visual midline in humans. Neuropsychologia, 16, 601-610.

Haun, F. (1978). Functional dissociation of the hemispheres using foveal visual input. Neuropsychologia, 16, 725-733.

Hilgetag, C. C., Theoret, H., \& Pascual-Leone, A. (2001). Enhanced visual spatial attention ipsilateral to rTMS-induced "virtual lesions" of human parietal cortex. Nature Neuroscience, 4, 953-957.

Iacoboni, M., \& Zaidel, E. (1996). Hemispheric independence in word recognition: Evidence from unilateral and bilateral presentations. Brain and Language, 53, 121-140.

Jordan, R. T., Patching, G. R., \& Milner, A. D. (2000). Lateralized word recognition: Assessing the role of hemispheric specialization, modes of lexical access, and perceptual asymmetry. Journal of Experimental Psychology: Human Perception and Performance, 26, 1192-1208.

Kammer, T. (1999). Phosphenes and transient scotomas induced by magnetic stimulation of the occipital lobe: Their topographic relationship. Neuropsychologia, 36, 191-198.

Kammer, T., \& Nusseck, H. G. (1998). Are recognition deficits following occipital lobe TMS explained by raised detection thresholds? Neuropsychologia, 36, 1161-1166.

Kastner, S., Demmer, I., \& Ziemann, U. (1998). Transient visual field defects induced by transcranial magnetic stimulation over human occipital pole. Experimental Brain Research, $118,19-26$.
Kucera, H., \& Francis, W. N. (1967). Computational analysis of present day American English. Providence, RI: Brown University Press.

Lavidor, M., \& Ellis, A. W. (2002a). Word length and orthographic neighborhood size effects in the left and right cerebral hemispheres. Brain and Language, 80, 45-62.

Lavidor, M., \& Ellis, A. W. (2002b). Orthographic neighborhood effects in the right but not in the left cerebral hemisphere. Brain and Language, 80, 63-76.

Lavidor, M., Ellis, A. W., Shillcock, R., \& Bland, T. (2001). Evaluating a split processing model of visual word recognition: Effects of word length. Cognitive Brain Research, 12, 265-272.

Lavidor, M., Ellis, A. W., Shillcock, R., \& Hayes, A. (in press). Evaluating a split processing model of visual word recognition: Effects of orthographic neighborhood size. Brain and Language.

Lavidor, M., Ellison, A., \& Walsh, V. (in press). A virtual lesion examination of a split processing model of visual word recognition. Visual Cognition

Laxon, V., Masterson, J., \& Moran, R. (1994). Are children's representations of words distributed? Effects of orthographic neighborhood size, consistency and regularity of naming. Language and Cognitive Processes, 9, 1-27.

Laxon, V. J., Coltheart, V., \& Keating, C. (1988). Children find friendly words friendly too: Words with many orthographic neighbors are easier to read and spell. British Journal of Educational Psychology, 58, 103-119.

Leventhal, A. G., Ault, S. J., \& Vitek, D. J. (1988). The nasotemporal division in primate retina: The neural bases of macular sparing and splitting, Science, 240, 66-67.

Lines, C. R., \& Milner, A. D. (1983). Nasotemporal overlap in the human retina investigated by means of simple reaction time to lateralized light flash. Experimental Brain Research, 50, $166-172$.

McClelland, J. L., \& Rumelhart, D. E. (1981). An interactive activation model of context effects in letter perception: I. An account of basic findings. Psychological Review, 88, 375-407.

Miller, M. B., Fendrich, R., Eliassen, J. C., Demirel, S., \& Gazzaniga, M. S. (1996). Transcranial magnetic stimulation: Delays in visual suppression due to luminance changes. NeuroReport, 7, 1740-1744.

Morrison, C. M., \& Ellis, A. W. (2000). Real age of acquisition effects in word naming. British Journal of Psychology, 91, $167-180$.

Oldfield, D. P. (1971). The assessment and analyses of handedness. The Edinburgh Inventory. Neuropsychologia, 9, $97-113$.

O'Regan, J. K. (1981). The convenient viewing hypothesis, In D. F. Fisher, R. A. Monty, \& J. W. Senders (Eds.), Eye movements: Cognition and visual perception (pp. 289-298). Hillsdale, NJ: Erlbaum.

O'Regan, J. K., Levy-Schoen, A., Pynte, J., \& Brugaillere, B. (1984). Convenient fixation location within isolated words of different length and structure. Journal of Experimental Psychology: Human Perception and Performance, 10, 250-257.

Pascual-Leone, A., \& Walsh, V. (2001). Fast back projections from the motion to the primary visual area necessary for visual awareness. Science, 292, 510-512.

Patching, G. R., \& Jordan, T. R. (1998). Increasing the benefits of eye-tracking devices in divided visual field studies of cerebral asymmetry. Behavior Research Methods, Instruments and Computers, 30, 643-650.

Perea, M. (1998). Orthographic neighbors are not all equal: Evidence using an identification technique. Language and Cognitive Processes, 13, 77-90. 
Perea, M., \& Pollatsek, A. (1998). The effects of neighborhood frequency in reading and lexical decision. Journal of Experimental Psychology: Human Perception and Performance, 24, 767-779.

Portin, K., \& Hari, R. (1999). Human parieto-occipital visual cortex: Lack of retinotopy and foveal magnification. Proceedings of the Royal Society B, 266, 981-985.

Quinlan, P. (1993). The Oxford psycholinguistic database. Oxford: Oxford University Press.

Rayner, K. (1998). Eye movements in reading and information processing: 20 years of research. Psychological Bulletin, 124, 373-422.

Rubinstein, O., Henik, A., \& Dronkers, N. F. (2001). Is the right bemisphere capable of reading and understanding a word? Presented in ESCOP, Edinburgh, 4-7 September.

Segui, J., \& Grainger, J. (1990). Priming word recognition with orthographic neighbors: Effects of relative prime target frequency. Journal of Experimental Psychology: Human Perception and Performance, 16, 65-76.

Seyal, M., Ro, T., \& Rafal, R. (1995). Increased sensitivity to ipsilateral cutaneous stimuli following transcranial magnetic stimulation of the parietal lobe. Annals of Neurology, 38, $264-267$

Shillcock, R., Ellison, T. M., \& Monaghan, P. (2000). Eye-fixation behavior, lexical storage and visual word recognition in a split processing model. Psychological Review, 107, 824-851.

Stein, J., \& Walsh, V. (1997). To see but not to read; The magnocellular theory of dyslexia. Trends in Neuroscience, $20,147-152$.

Stewart, L., Battelli, L., Walsh, V., \& Cowey, A. (1999). Motion perception and perceptual learning: A magnetic stimulation study. Electroencephalography and Clinical Neurophysiology, 51, 334-350.

Stewart, L., Ellison, A., Walsh, V., \& Cowey A. (2001). Transcranial magnetic stimulation in studies of vision, attention and language. Acta Psychologica, 107, 275-291.
Stone, J. (1966). The naso-temporal division of the cat's retina. Journal of Comparative Neurology, 136, 585-600.

Stone, J., Leicester, J., \& Sherman, S. M. (1973). The naso-temporal division of the monkey's retina. Journal of Comparative Neurology, 150, 333-348.

Stuart, G. W., \& Lovegrove, W. J. (1992). Visual processing deficits in dyslexia-receptors or neural mechanisms. Perceptual and Motor Skills, 74, 187-192.

Sugishita, M., Hamilton, C. R., Sakuma, I., \& Hemmi, I. (1994). Hemispheric representation of the central retina of commissurotomized participants. Neuropsychologia, 32, $399-415$.

Trauzettel-Klosinski, S., \& Reinhard, J. (1998). The vertical field border in hemianopia and its significance for fixation and reading. Investigative Ophthalmology and Visual Science, 39, 2177-2186.

Walsh, V., \& Cowey, A. (1998). Magnetic stimulation studies of visual cognition. Trends in Cognitive Sciences, 2, 103-110.

Walsh, V., \& Cowey, A. (2000). Transcranial magnetic stimulation and cognitive neuroscience. Nature Reviews Neuroscience, 1, 73-79.

Walsh, V., Ellison, A., Ashbridge, E., \& Cowey, A. (1999). The role of the parietal cortex in visual attention-hemispheric asymmetries and the effect of learning: A magnetic stimulation study. Neuropsychologia, 37, 245-251.

Walsh, V., \& Pascual-Leone, A. (2003). Transcranial magnetic stimulation: A neurochronometrics of mind. Cambridge: MIT press.

Wyatt, H. J. (1978). Nasotemporal overlap and visual field sparing. Investigative Ophthalmology and Visual Science, 17, $1128-1130$.

Ziegler, J. C., \& Perry, C. (1998). No more problems in Coltheart's neighborhood: Resolving neighborhood conflicts in the lexical decision task. Cognition, 68, B53-B62.

Zihl, J. (1989). Cerebral disturbances of elementary visual functions. In J. W. Brown (Ed.), Neuropsychology of the visual perception (pp. 35-58). Hillsdale, NJ: Erlbaum. 